\title{
Comparison of Different Waste Management Technologies and Climate Change Effect-Jordan
}

\author{
Mohammad Aljaradin ${ }^{1}$, Kenneth M. Persson ${ }^{1,2}$ \\ ${ }^{1}$ Department of Water Resources Engineering, Lund University, Lund, Sweden \\ ${ }^{2}$ Sydvatten AB, Malmö, Sweden \\ Email: mohammad.aljaradin@tvrl.lth.se
}

Received March 12, 2012; revised April 14, 2012; accepted April 26, 2012

\begin{abstract}
Solid waste management (SWM) strategies offer huge potentials to contribute to climate change mitigation. To assess the potentials of SWM to contribute to greenhouse gas (GHG) reduction and resource recovery, available technologies and strategies have to be analyzed. In this work, a SWM-GHG calculator was used to compare different potential strategies for waste management considering economic situation, environmental and social awareness in Jordan. Four scenarios representing the current and suggested technologies (increase recovery, biological treatment, and advance biological treatment) were studied. The results showed that a vast reduction of GHG emission of about 63,175 tons $\mathrm{CO}_{2 \text {-eq }}$ year was observed in the fourth scenario where all the organic waste was recovered. Moreover, this scenario increased the net caloric values in reused waste from 8.4 to $9.6 \mathrm{MJ} / \mathrm{kg}$. The results suggest that the SWM-GHG calculator can offer sufficiently accurate approximation of the GHG impacts of different suggested strategies in the country and can serve as an important contribution to decision makers.
\end{abstract}

Keywords: Greenhouse Gas; Climate Change; SWM-GHG Calculator; Jordan

\section{Introduction}

Jordan has seen a large increase in inhabitants over the past five decades as a result of a high population growth rate and forced migrations. Economic and cultural development has improved the standard of living and changed consumer habits, resulting in an increase in the volume of municipal solid waste (MSW) over time. The rate of production of MSW has been estimated at about $1,960,000$ tons annually with an average generation rate of $0.95 \mathrm{~kg} / \mathrm{cap} /$ day in urban and $0.85 \mathrm{~kg} / \mathrm{cap} /$ day in rural areas [1] and is expected to reach 2.5 million tons by 2015. The solid waste volume is still increasing at high rates due to the rapid population increase as well as the change in living standards and consumption patterns.

Landfilling is the simplest and normally cheapest method for disposing of waste [2]. Despite waste reducetion and recycling policies and waste pretreatment programs to lower the proportion of waste going to landfill, landfills will still be required to accommodate residual wastes. However, although the proportion of waste to landfill may be decreasing, the total volumes of MSW being produced are still increasing significantly $[3,4]$. In Jordan, landfilling of MSW has evolved over the past 15 years as recommended disposal method. From 1950, waste disposal basically involved open dumping and burning without complying with the proper regulations, while in the beginning of the 1980s, awareness of the need to establish sanitary landfills increased. Until now, Jordan has relied only on landfills to store the waste. Recently, numerous recycling initiatives have been implemented for various components of the solid waste stream at different stages of the waste management process in Jordan. These initiatives have mainly been established by the private sector and as a general rule the process is not well managed by the state. Recycling activities at times are undertaken before the solid waste reaches the final disposal sites for the separation of recyclable materials, paper, metals and plastics; at the disposal sites much of the work is carried out by children and young person's acting as scavengers. These operations lack in regulation and environmental auditing and workers are often exposed to hazardous conditions.

Despite the intensive efforts that are directed to the recycling and recovery of solid wastes, landfills remain and will remain an integral part of most SWM strategies in the country. The decomposable and recyclable materials in the MSW is about $86 \%$, while the remainder is inert (Figure 1), the major fraction is organic, which implies a high moisture content value, as expected in a developing country where food residuals are the major component of the solid waste stream [5]. 


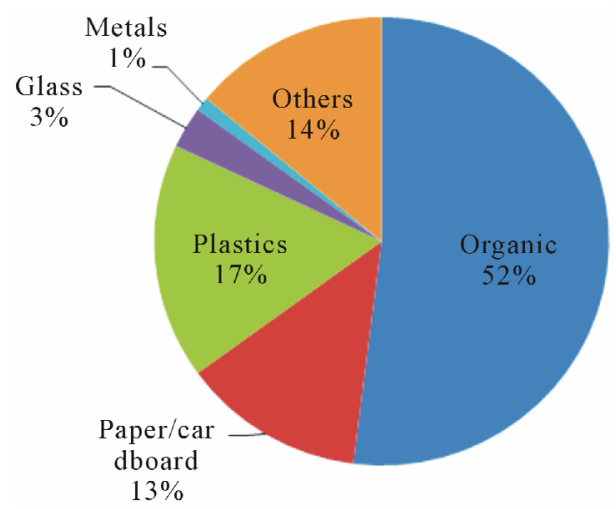

Figure 1. The physical composition of MSW in Jordan (source: SWEEP 2010).

Since the waste streams are rich in biodegradable materials, the potential to reduce greenhouse gas emissions is significant. Several gases are generated by decomposition process of organic materials in a solid waste landfill. The composition, quantity, and generation rates of the gases depend on several factors such as refuse quantity, density and composition, placement characteristics, landfill depth, refuse moisture content, temperature, and amount of oxygen present. Most organic materials are biodegradable and can be broken down into simpler compounds by aerobic and anaerobic microorganisms, leading to the formation of gas and leachate [6]. Emissions from landfills have received great attention in Jordan due to the mounting awareness of the potential adverse impact these emissions may have on public health and the environment, yet few studies have focused on the quantity and quality of these emissions. Environmental and health concerns, coupled with the ever-increasing cost of new landfills, have forced the authorities to look for alternative methods to deal with the problem of waste disposal. Considerable efforts are being made by governments and many non-governmental organizations (NGOs) to tackle waste-related problems, yet there are still major gaps to be filled in this area. The World Bank estimates that in developing countries, it is common for municipalities to spend $20 \%-50 \%$ of their available budget on solid waste management. Hence, developing countries face uphill challenges to properly manage their waste with most efforts being made to reduce the final volumes and to generate sufficient funds for waste management. If most of the waste could be diverted for material and resource recovery, then a substantial reduction in final volumes of waste could be achieved and the recovered material and resources could be utilized to generate revenue to fund waste management. Recent studies have proven that an improvement of disposal systems (complete collection, upgrading to sanitary landfilling) is the most cost-effective method to reach the objectives of SWM in developing countries [7].

\section{Climate Change Effect}

\subsection{Climate Change Policies}

Climate change is not only a major global environmental problem, but also an issue of great concern to developing country like Jordan [8]. Jordan is not contributing to more than $0.05 \%$ to the world total GHG emissions. This relatively small contribution of GHGs does not correspond to the projected impacts of climate change for the country [9]. Jordan will mainly be negatively impacted by the climate change [10]. However, on a policy level, Jordan is strongly committed to the objectives developed by the international community to reduce the threat of climate change. The United Nations framework convention on climate change (UNFCCC) was approved in the country in 1993. The main focal point for environmental policy and climate change issues in Jordan is the Ministry of environment which was established in 2003, and it functions within the mandate of Environmental Protection Law No: 1/2003. The Ministry's responsibilities include developing government guidelines and policies concerning the environment, and the coordination of climate change activities [11]. Climate change is however not a priority issue among other environmental issues in the country at present. Still, in 2004, the government set policy goals and objectives which formed the framework of the renewable energy target. They aim for a 5\% share in the primary energy mix by the year 2015. The policy goals include reducing the country's emissions of GHGs and optimizing the emission reduction benefits through the sale of emission reduction credits in the global carbon markets. Working on minimizing the climate change effects in Jordan will remain ineffective to a large extent without economic incentives. One such important incentive is the suggested in the Kyoto Protocol. Developed countries should have a precise responsibility in accordance with the commitments made under it by assisting developing countries Through extending and supporting the Kyoto mechanisms such as the clean development mechanism (CDM) that allow developed countries payments for GHG emissions reductions to developing countries [12]. The Kyoto Protocol was accepted by Jordan in 2003 and in 2005 it came into force. The payments will encourage and increase worldwide rates of landfill $\mathrm{CH}_{4}$ recovery. The total global economic mitigation potential for reducing landfill $\mathrm{CH}_{4}$ emissions in 2030 is estimated to be $70 \%$ at costs below 100 US $\$ /$ ton $\mathrm{CO}_{2}$ equivalents $\left(\mathrm{CO}_{2-\mathrm{eq}}\right) / \mathrm{yr}$, thus providing a good market for $\mathrm{CO}_{2}$ revenue.

The last IPCC report puts the contribution made by the solid waste and wastewater management sector to global GHG emissions at $2.7 \%$, which might appear to be comparatively low compared to for example the energy sector. But in fact, improved waste management can con- 
tribute indirectly to significantly larger GHG emissions reductions. In the year 2000, GHG emissions to the atmosphere from the waste sector totaled $2713 \mathrm{Gg} \mathrm{CO}_{2 \text {-eq }}$ or $13.5 \%$ of Jordan's total GHG emissions. This can be compared with the energy sector contribution of around $14911 \mathrm{Gg} \mathrm{CO}_{2 \text {-eq }}$, or $74.0 \%$ of the total contribution from Jordan. [13] Giegrich and Vogt [14] predicted that developing countries could reduce their GHG emissions by around 5\% merely by adopting municipal waste management systems using current technologies. Moreover, including other waste types, especially waste containing high levels of biodegradable organic matter, the reducetion of GHG emissions in these countries could be doubled.

GHG emissions from waste are directly affected by numerous policy and regulatory strategies that encourage energy recovery from waste, restrict choices for ultimate waste disposal, promote waste recycling and re-use, and encourage waste minimization. In developing countries, major policies are aimed at restricting the uncontrolled dumping of waste. Still, these policies don't integrate with climate policies. However, estimation the costs of reducing GHG emissions tend to vary a lot across different models and studies. Also, it is clear that modeling work in the field of climate policy has its limitation, and there is need for additional research. One of most important limitations of climate policy modeling concerns the long-term potential for technological progress and the evolution of new technological ways [15].

\subsection{Climate Change and Green House Gases}

Globally, most MSW is dumped in non-regulated landfills where landfill gas (LFG) is generated as a by-product. LFG is produced when organic material decomposes anaerobically, consisting of $45 \%$ to $60 \%$ methane gas, $40 \%$ to $60 \%$ carbon dioxide, and $2 \%$ to $9 \%$ other gases which are mostly emitted to the atmosphere. Climate change is caused by an increasing level of GHG in the atmosphere. Methane gas is a GHG that is 23 times more harmful than the same volume of carbon dioxide [10]. One of the main sources for methane is landfills and most of the methane gas produced from the landfills leaks into the atmosphere and contribute to global warming. Biogas from landfills has been collected and sometimes used for several decades in many industrialized countries and it has a proven record as an environmentally sound technology. Jordan has relatively good potential to utilize the biogas from solid waste especially with the success of the Rusaifeh LFG plant. The main objective for this project was to reduce the GHG emissions from the Rusaifeh closed landfill and to provide an energy recovery opportunity [16]. [17] estimated that the mitigation of methane gas from two landfills (al Rusaifeh and Akaider landfills) could be used to generate electricity at a cost of 4.6 cents per $\mathrm{kWh}$, which is less than the Jordan electric long-run marginal cost of generation at 5.5 cents $/ \mathrm{kWh}$. Moreover, annual savings of US $\$ 4.65$ million would be achieved by the replacement of fuel oil with the generated biogas. In addition, it was found that the methane production in Akaider landfill will reach 12 Million $\mathrm{m}^{3} /$ year by the year 2021 if it is utilized properly; the biogas will not only generate a green energy, but could also create a source of revenue through selling it through CDM. Jordan, as many other countries in the region, will have the opportunity to include LFG and biogas projects as potential projects that will add to the country's sustainable development through CDM of the carbon market $[18,19]$.

Utilizing the GHG is very important in terms of improving the environment and climate and to help protecting human health. In terms of recovering materials, the proper selection of waste management technologies that will allow for more efficient and cost-effective waste treatment must be consider prior final decision. In this work, a SWM-GHG Calculator has been used for quantification and comparison of GHG emissions of different waste management strategies in the country, through a calculation of the GHG emissions of the different recycled and disposed waste fractions.

\section{Method and Materials}

\subsection{MSW-GHG Calculators}

The (SWM-GHG) calculator used in this study was developed by IFEU Institute, sponsored by German Financial Development in cooperation with GTZ (German Technical Development Cooperation) and financed with funds provided by the German Federal Ministry for Economic Cooperation and Development [20]. It is based on Excel as a common spreadsheet application and uses the theoretical gas yield methodology to compare different waste management technologies options. In this tool, the user can roughly assess the climate effects of waste management strategies even in very early steps of the decision making process. This may give firsthand information for waste management planning to Municipality, consultant or even the public.

The calculation method used in the SWM-GHG Calculator follows the Life Cycle Assessment (LCA) method. Different waste management strategies can be compared by calculating the GHG emissions of the different recycled and disposed of waste fractions over their whole life. The tool sums up the emissions of all residual waste or recycling streams respectively and calculates the total GHG emissions in $\mathrm{CO}_{2 \text {-eq. }}$ The emissions calculated also include all future emissions caused by a given quantity of treated waste. This method corresponds to the "Tier 1" approach described in [21]. The tool contains basic rou- 
tines for calculation of GHG emissions by typical waste management technologies such as controlled dump, landfill with and without gas collection, mechanical-biological treatment of waste prior to deposition, mechaniccal-physical stabilization and co-processing in cement kilns, recycling of waste components, composting and digestion of organic components. The user can choose which options to be compared. The tool provides a set of default values that required during comparison. On the other hand, user can use his own data. For more details about the SWM-GHG see the manual by [20].

\subsection{Input Data}

Scenarios for waste management option and technologies to be chosen were identified considering the economic and environmental constriction in the country. Also to what extent the scenarios could be applied in the field was evaluated. The First scenario is the current situation, referred and designed to assess the present condition in Jordan, where most of the waste is dumped, either in open dump site or in controlled landfills. The formal material composition of municipal solid waste was used. In addition, informal recycling which was estimated in a survey conducted in 2010 was considered (Aljaradin, unpublished data). The purpose of that survey was to identify the role of scavengers in waste management in Jordan. The recovered materials represent $20 \%$ of the waste generation in the area of the case study. Figure 2 presents the percentage of these recyclable materials.

Scavengers play a major role in the resource recovery process and environment protection through reducing the volume of waste disposed. The scavengers' work was found to be very efficient, since they recover high quantities of recyclables materials. Figure 3 represented the observed quantities collected by 100 scavengers during a working day.

Thus, informal waste recycling that already exists in some part of the country reduce the cost of formal waste management systems as they reduce the quantity of waste for collection, resulting in less money and time spent on collection and transport [22,23]. Therefore, in this scenario we will take into account the scavenger contribution.

In the second scenario, it was assumed that more work is done in separation at the source of waste collection in order to comply with the recycling initiatives, according to the strategies suggested by authorities and country policy for waste management in Jordan [13]. This improvement was introduced in the recent national strategies through the following option: Strengthen the national and the municipal capacities to promote private sector involvement in the solid waste field. Adoption of integrated SWM approaches with the aim to improve

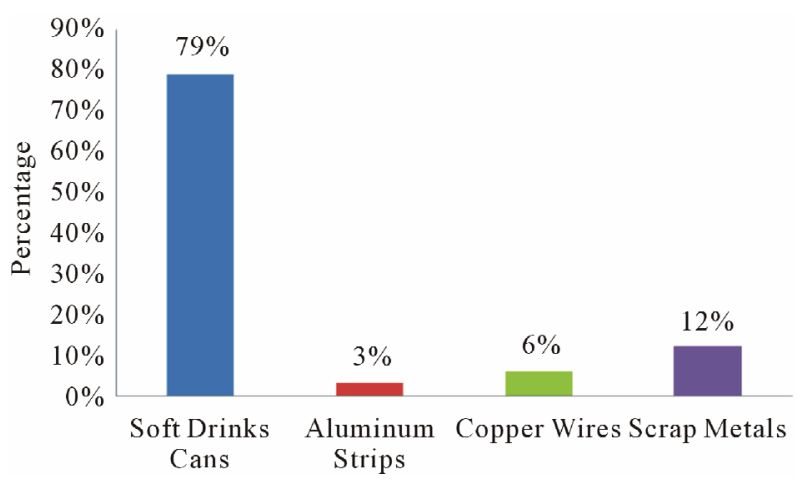

Figure 2. Percentage of the recyclable quantities collected by scavengers during a working day (source: field work 2/10/2010).

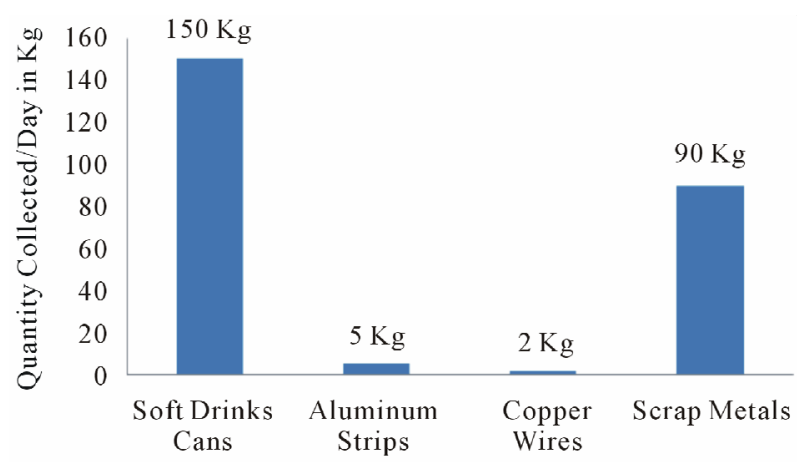

Figure 3. Average quantities collected by 100 scavenger during a working day (source: field work $2 / 10 / 2010$ ).

collection, transfer, and disposal with cost-effective resource recovery and recycling based on the "polluter pays and user pays" principle and also by increasing the awareness among people for environmental, economical and social benefits of recycling.

In the third scenario, it was assumed that the country will adapt a technology which can deal with the organic fractions in the waste through treatment in biogas plants with anaerobic digestion, which not only provides pollution prevention, but also allows for sustainable energy and material recovery. A biogas plant can convert a disposal problem into a profit center in term of reduction and recovery of a renewable fuel and other valuable coproducts [24]; in practice, this could be achieved by increasing the Rusaifeh biogas plant capacity which would reduce the landfilled organics to $30 \%$. This suggestion has been proposed for future development of the $\mathrm{Ru}$ saifeh LFG plant $[16,17,24]$. It should be noticed that LFG and anaerobic biogas plants are seriously considered in Jordan as well as in the Middle East region [24].

The fourth scenario assumed the establishment of a fully sanitary landfill where anaerobic composting and digestion are carried out. Up to $60 \%$ of the organic fraction of waste is assumed to be processed.

Table 1 represents the population, waste Generation 
Table 1. Summary of input data for the SWM-GHG calculator.

\begin{tabular}{ccc}
\hline Population & Million & 5.8 \\
\hline Waste Generation & tons/a & $1,964,284$ \\
$\begin{array}{c}\text { Country Specific CO } \\
\text { for Electricity Generation }\end{array}$ & $\mathrm{g} \mathrm{CO}_{2} / \mathrm{kwh}$ & 1631 \\
\hline
\end{tabular}

quantities [1], and Country-specific GHG emission factor for generation of electricity [20], which is used for the basic input data for the GHG calculator.

Figure 4 represent the data on present and suggested waste disposal practices which were taking into account in the GHG calculator. The engineered landfills represent the $\mathrm{Al}$ Ghabawi landfill of the Greater Amman Municipality, which receives more than $50 \%$ of the generated solid waste in Jordan in terms of volume and which was designed according to international standards.

The total annual costs (capital costs, operating costs, replacement, additional costs, etc.) which is related to the theoretical gate fees for different scenarios were calculated based on previous studies $[25,26]$. The suggested cost used for controlled dump and landfill without gas collection, sanitary landfill with gas collection and advanced biological treatment were 3, 12 and 15 Euros/ton, respectively.

\section{Results and Discussion}

In the first scenario, the current situation in Jordan is considered where most of the waste is landfilled as shown in Figure 4. The recovered material was estimated based on the survey conducted in 2010, where Glass, Ferrous metals and Aluminum is up to $40 \%$, Paper, cardboard, Plastics, Textiles is up to $10 \%$, and organics mainly from food is up to $10 \%$ used for electricity generation through an LFG plant. The calculated GHG emission was as 1,971,633 ton $\mathrm{CO}_{2 \text {-eq }} /$ year, as seen in Figure 5. The calculated caloric value is $8.6 \mathrm{MJ} / \mathrm{kg}$ and the total annual cost for the current situation is $2,657,676$

\section{Euro/year.}

In the second scenario, we assumed that the waste will be disposed of in engineered landfills and controlled dumps. The only change from the first scenario to the second, is that open dumping will be stopped, and the recycling increased by $10 \%$, whereas, paper and cardboard recovery increase up to $40 \%$ and plastic, ferrous metal and aluminum up to $20 \%$. The result showed the GHG emissions reduced from 1,971,633 ton $\mathrm{CO}_{2 \text {-eq }} /$ year to $1,531,333$ ton $\mathrm{CO}_{2 \text {-eq }} /$ year. This reduction cannot be achieved unless the authorities start to increase the awareness among the public regarding recycling (practices, benefits, and responsibilities) in regular program and with the suitable tools. In addition, more organized work for scavengers and private sector involvement must be implemented. In this scenario the caloric value and the total annual cost is decreased to $7.6 \mathrm{MJ} / \mathrm{kg}$ and $2,380,712$ Euro/year respectively. The cost decrease is solely due to savings in less need for landfilling, attributed to the increase in waste recovery, without considering the energy value in collected landfill gas.

In scenarios 3 and 4, launching of new biological treatment technologies and an upgrading of the existing LFG plants were considered. This could be implemented by establishing a new well equipped engineered landfill and stopping the controlled dumping, as first step, followed by the construction of gas collection facilities. Moreover, in scenario 3 we considered that all the recovered organic waste will be digested, and in scenario 4 we considered $60 \%$ of the recovered organic waste digested and $40 \%$ is used for compost production. The result showed a clear reduction of GHG emissions. A biogas plant is an efficient technology for utilization of organic waste for the production of electricity and composting without releaseing GHG into the atmosphere and it has a proven record as an environmentally sound technology. For scenarios 3 and 4, the GHG emissions reduced to 726,944 and 63,175 ton $\mathrm{CO}_{2 \text {-eq }} / \mathrm{year}$ and the calculated caloric value is 8.4 and $9.6 \mathrm{MJ} / \mathrm{kg}$ respectively. On the other hand, the

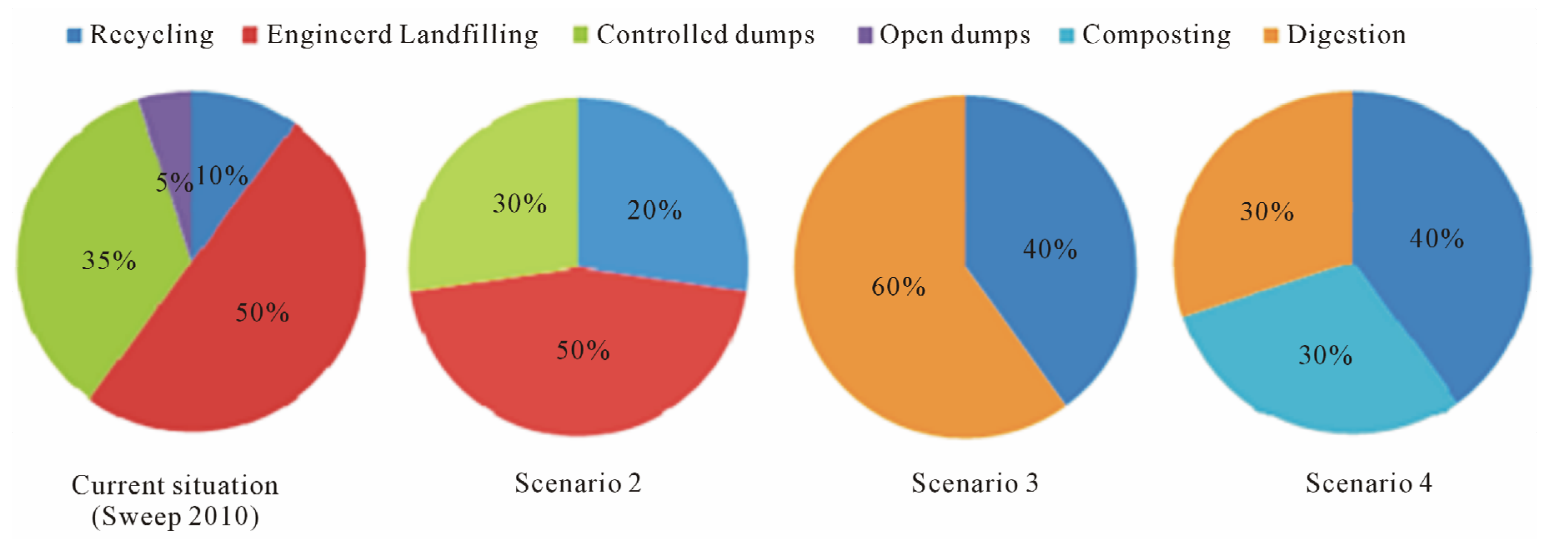

Figure 4. Present and suggested municipal solid waste disposal practice in Jordan. 


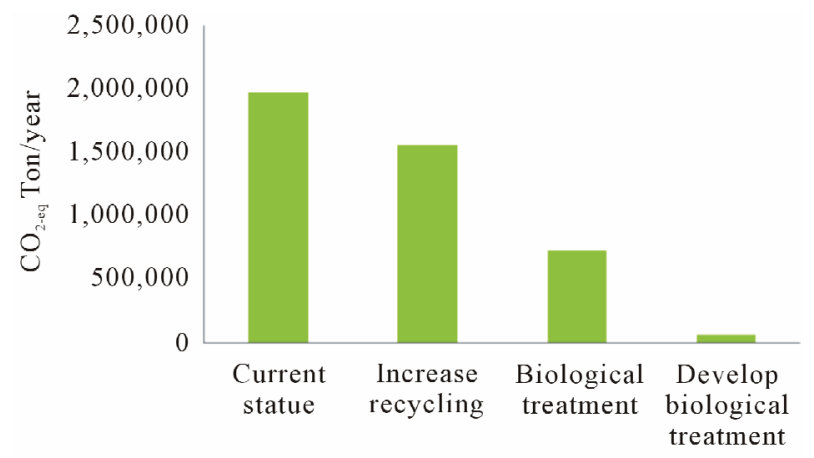

Figure 5. Comparison of GHG emissions for different waste management scenario (source: based on SWM-GHG calculator).

total annual cost for implementing such technology was 9,956,563 and 9,692,563 Euro/year for scenarios 3 and 4 respectively.

In Table 2, a summary of the four scenarios with costs and GHG reductions is presented. Scenario 2 is immediately profitable, since the total cost will be reduced for this management solution, yet this scenario has a minor effect on GHG reductions to the atmosphere compared to scenarios 3 or 4 . If the reduced GHG-emission could be sold in the carbon capping trade system for a prize higher than the actual cost of implementing GHG reductions in Jordan, the net effect of scenario 3 and 4 will not only be a significantly reduced environmental load of GHG to the atmosphere, but will also be an economically profitable business. Typically, the value of GHG emission reductions in the carbon capping trade system has been in the range of $10-15 € /$ ton. Hence the different scenarios 2 - 4 deserve to be analyzed in more detail.

\section{Conclusions}

SWM-GHG Calculators can be used to assess the impact of different waste management strategies for a country. Overall, we believe that our findings provide clear insights in which different strategies for waste management that can and should be applied in Jordan. The SWMGHG Calculator offers a sufficiently accurate approximation of the GHG impacts of different strategies and is thus an important support for decision makers.

The current waste management strategy in Jordan is not environmentally sustainable, since it relies only on landfills to dump the waste in. It is evident that waste management strategies only focusing on landfilling will lead to high GHG emissions.

Based on the results of GHG emission assessments conducted for several SWM scenarios by utilizing the SWM-GHG Calculator, a vast reduction of GHG emission was observed in the fourth scenario where the organic waste was recovered of about 63,175 tons $\mathrm{CO}_{2 \text {-eq }}$ / year, especially if organic waste is recovered and either
Table 2. Technical and economic summary of investing in GHG emission reductions for Jordanian landfills.

\begin{tabular}{ccccc}
\hline S. no. $\begin{array}{c}\text { GHG emission } \\
\text { (M. ton) }\end{array}$ & $\begin{array}{c}\text { Cost } \\
(\mathrm{M} . €)\end{array}$ & $\begin{array}{c}\text { Savings of GHG } \\
\text { emission (M. ton } \\
\text { in relation to S.1) }\end{array}$ & $\begin{array}{c}\text { Cost of GHG } \\
\text { emission } \\
\text { reduction }(€ / \text { ton })\end{array}$ \\
\hline 1 & $1,971,633$ & 2.66 & 0 & n.a. \\
2 & $1,531,333$ & 2.38 & 440,300 & -0.64 \\
3 & 726,944 & 9.96 & $1,244,689$ & 5.86 \\
4 & 63,175 & 9.69 & $1,908,458$ & 3.68 \\
\hline
\end{tabular}

${ }^{*}$ M.: million; S.: scenario.

composted or treated with in anaerobic bioreactors. This enormous reduction is concurring with the country polices for clean environment and sustainable energy recovery. An increased waste recycling and reuse would be economically beneficial for Jordan, since the costs for landfilling would decrease as the utilization of material increases. Although the total annual cost was relatively higher in scenarios 3 and 4, the mitigation costs per ton of GHG emissions were distinct. Therefore, the fourth scenario will be most cost effective among the four taking into account its benefits.

Increasing recovery of recyclable material through organized work of scavenger and increasing the investment and the involvement of private sector in this field will help to achieve the goal.

Adapting these improved waste treatment technologies in Jordan could be beneficial taking into account the GHG emission reduction and higher caloric value generated. However, great attention should be paid to the public awareness for source separation and recovery process as the first step forward. Other countries with similar conditions as Jordan should experience the same benefits from improved waste management. However, local conditions, baseline and cost assumptions and economic and social expansion issues for adapting such alternative waste management strategies need of course to be carefully defined for these countries. One first step is to use the SWH-GHG calculator when assessing the GHGemission and potential savings for them.

\section{REFERENCES}

[1] SWEEP, "Country Profile on Solid Waste Management Situation," The Regional Solid Waste Exchange Information and Expertise Network in Mashreq and Maghreb Countries, 2010.

[2] R. Taylor and A. Allen, "Waste Disposal and Landfill: Potential Hazards and Information Needs," 2003.

http://www.bvsde.paho.org/bvsacd/cd59/protecting/sect212.pdf

[3] A. Alistair, "Attenuation: Landfills the Future in Landfil- 
ling," 2000.

http://wbiis.tu.koszalin.pl/towarzystwo/2000/17allen_t.pdf

[4] P. Beigl and S. Lebersorger, "Forecasting Municipal Solid Waste Generation for Urban and Rural Regions," The 12th International Waste Management and Landfill Symposium, Cagliari, 5-9 October 2009.

[5] H. Abu Qdais, "Environmental Impact Assessment of Municipal Solid Waste Landfills: A Case Study from Jordan," The 11th International Waste Management and Landfill Symposium, Cagliari, 1-5 October 2007.

[6] M. El-Fadel, A. Findikakis and J. Leckie, "Environmental Impacts of Solid Waste Landfilling," Journal of Environmental Management, Vol. 50, No. 1, 1997, pp. 1-25. doi:10.1006/jema.1995.0131

[7] P. Brunner and J. Fellner, "Setting Priorities for Waste Management Strategies in Developing Countries," Waste Management \& Research, Vol. 25, No. 3, 2007, pp. 234240.

[8] F. Abdulla and A. Al-Omari, "Impact of Climate Change on the Monthly Runoff of a Semi-Arid Catchment: Case Study Zarqa River Basin (Jordan)," Journal of Applied Biological Sciences, Vol. 2, No. 1, 2008, pp. 43-50.

[9] WRI, "Earth Trends Data Tables: Climate and Atmosphere," 2005. http://www.earthtrends.wri.org/

[10] IPCC, "Climate Change 2007: Iimpacts, Adaptation and Vulnerability," Cambridge University Press, Cambridge, 2007.

[11] M. Environment, “Jordan's Second National Communication to the United Nations Framework Convention on Climate Change (UNFCCC)," UNFCCC, Amman, 2009.

[12] UNDP, "Keeping the Promise and Achieving Aspirations," Ministry of Planning and International Cooperation United Nations in Jordan, Amman, 2010.

[13] UNDP, "Jordan Second National Communication to the United Nations Framework Convention on Climate Change (UNFCCC)," Jordan Ministry of Environment, Amman, 2009.

[14] J. Giegrich and R. Vogt, "Strategy Proposals for Optimising German Development Cooperation-Contribution to GHG Mitigation in the Waste Management Sector," Deutsche Gesellschaft für Technische Zusammenarbeit (GTZ), Eschborn, 2008.

[15] P. Söderholm, "Modeling the Economic Costs of Climate Policy: An Overview," American Journal of Climate Change,
Vol. 1, No. 1, 2012, pp. 14-32.

[16] METAP, "Development of Strategic Framework for Private Sector Participation in MSW Management Report," Ministry of Environment Jordan, Amman, 2008.

[17] Z. Al-Ghazawi and F. Abdulla, "Mitigation of Methane Emissions from Sanitary Landfills and Sewage Treatment Plants in Jordan," Clean Technologies and Environmental Policy, Vol. 10, No. 4, 2008, pp. 341-350. doi:10.1007/s10098-008-0145-8

[18] H. Abu Qdais and F. Abdulla, "Solid Waste Landfills as a Source of Green Energy: Case Study of Al Akeeder Landfill," The International Conference and Exhibition on Green Energy \& Sustainability for Arid Regions \& Mediterranean Countries, Amman, 10-12 November 2009.

[19] M. Aljaradin and K. M. Persson, "Design of Sanitary Landfills in Jordan for Sustainable Solid Waste Management," Journal of Applied Sciences Research, Vol. 6, No. 11, 2010, pp. 1880-1884.

[20] J. Giegrich and R. Vogt, "Tool for Calculating Greenhouse Gases (GHG) in Solid Waste Mangement (SWM)," KFW Entwicklungsbank, Frankfurt, 2009.

[21] IPCC, "Guidelines for National Greenhouse Gas Inventories,” In: H. S. Eggleston, L. Buendia, K. Miwa, T. Ngara and K. Tanabe, Eds., The National Greenhouse Gas Inventories Programme, IGES, Amman, 2006.

[22] D. Wilson, C. Velis and C. Cheeseman, "Role of Informal Sector Recycling in Waste Management in Developing Countries," Habitat International, Vol. 30, No. 4, 2006, pp. 797-808. doi:10.1016/j.habitatint.2005.09.005

[23] M. Aljaradin, K. M. Persson and H. Alitawi, "Public Awareness and Willingness for Recycle in Jordan," International Journal of Academic Research, Vol. 3, No. 1, 2011, pp. 508-510.

[24] Z. Al-Ghazawi, "Evaluation Report: Jordan Methane Capture and Utilization Demonstration Project," UNDP, Amman, 2004.

[25] KFW, "Financial Feasibility versus Environmental Soundness," German-Turkish Environmental Technology Workshop, Istanbul, 2008.

[26] Eunomia, "Costs for Municipal Waste Management in the EU," Environment European Commission, Eunomia Research \& Consulting on Behalf of Ecotec Research \& Consulting, Auckland, 2003. 